\title{
A Novel MPPT Technique for Single Stage Grid-Connected PV Systems: T4S
}

\author{
Luigi Costanzo *(1) and Massimo Vitelli \\ Department of Engineering, Università degli Studi della Campania “Luigi Vanvitelli", 81031 Aversa (CE), Italy; \\ massimo.vitelli@unicampania.it \\ * Correspondence: luigi.costanzo@unicampania.it; Tel.: +39-501-0212
}

Received: 21 October 2019; Accepted: 25 November 2019; Published: 26 November 2019

\begin{abstract}
In this paper, a novel maximum power point tracking (MPPT) technique, which has been named T4S (a technique based on the proper setting of the sign of the slope of the photovoltaic voltage reference signal), is presented and discussed. It is specifically designed with reference to a single-stage grid-connected PV system. Its performance is numerically compared with that of the well-known and widely used perturb and observe $(\mathrm{P} \& \mathrm{O}) \mathrm{MPPT}$ technique. The results of the numerical simulations confirm the validity of the proposed MPPT technique which exhibited a slightly better performance, under stationary and also time-varying irradiance conditions. In addition, the T4S technique is characterized by the following features: it does not require explicit power detection or calculation and, moreover, it allows the tracking of the maximum average power injected into the grid rather than the tracking of the maximum instantaneous power extracted by the PV source.
\end{abstract}

Keywords: photovoltaic systems; maximum power point tracking; single stage grid connected systems

\section{Introduction}

Maximum power point tracking (MPPT) is one of the main functions carried out by power electronic interfaces that connect photovoltaic (PV) sources to loads and grid. Many MPPT techniques have been presented and discussed in the literature [1-5]. Among them, the perturb and observe (P\&O) technique has emerged as one of the simplest, but nonetheless efficient, MPPT techniques and is widely accepted as a benchmark MPPT technique [6-8]. It can be adopted in both single- and double-stage grid-connected PV systems [9,10]. It works by perturbing the operating point of the PV source and observing the corresponding variation of the PV power in order to detect the direction of perturbation of the operating point (increase or decrease of the PV voltage) leading to the maximization of the PV extracted power [11,12]. In this paper, a novel MPPT technique is introduced and analyzed. It has been named T4S (a technique based on the proper setting of the sign of the slope of the photovoltaic voltage reference signal). It is designed with specific reference to a single-stage grid-connected PV system [13-15]. As shown in this paper, the tracking efficiency of the proposed T4S technique is more or less comparable to that of the $\mathrm{P} \& \mathrm{O}$ technique. However, the T4S technique is characterized by the following advantages with respect to the $\mathrm{P} \& \mathrm{O}$ technique: it does not require $\mathrm{PV}$ current detection and the power stage efficiency profile is automatically taken into account by tracking the maximum power injected into the grid rather than the maximum power extracted by the PV source.

The rest of the paper is organized as it follows: In Section 2 a typical single-stage grid-connected PV system is described together with the working of the P\&O MPPT technique. In Section 3, the proposed T4S MPPT technique is discussed and analyzed in detail. The main parameters affecting its performance are identified and proper guidelines for their choice are provided. In Section 4, numerical results are reported and discussed. In particular, both constant and time-varying irradiance profiles 
are considered in the numerical simulations. In Section 5 , the performance of the proposed T4S MPPT technique is compared with the $\mathrm{P} \& \mathrm{O}$ technique under both stationary and time-varying irradiance conditions. Finally, the conclusions are presented at the end of the paper.

\section{Single-Stage Grid-Connected PV System with P\&O Controller}

A typical single-stage grid-connected PV system is shown in Figure 1 [13-15]. The DC/AC converter is an active full bridge with a control circuitry exhibiting the presence of two control loops, an inner current control loop, and an outer voltage control loop $[16,17]$.

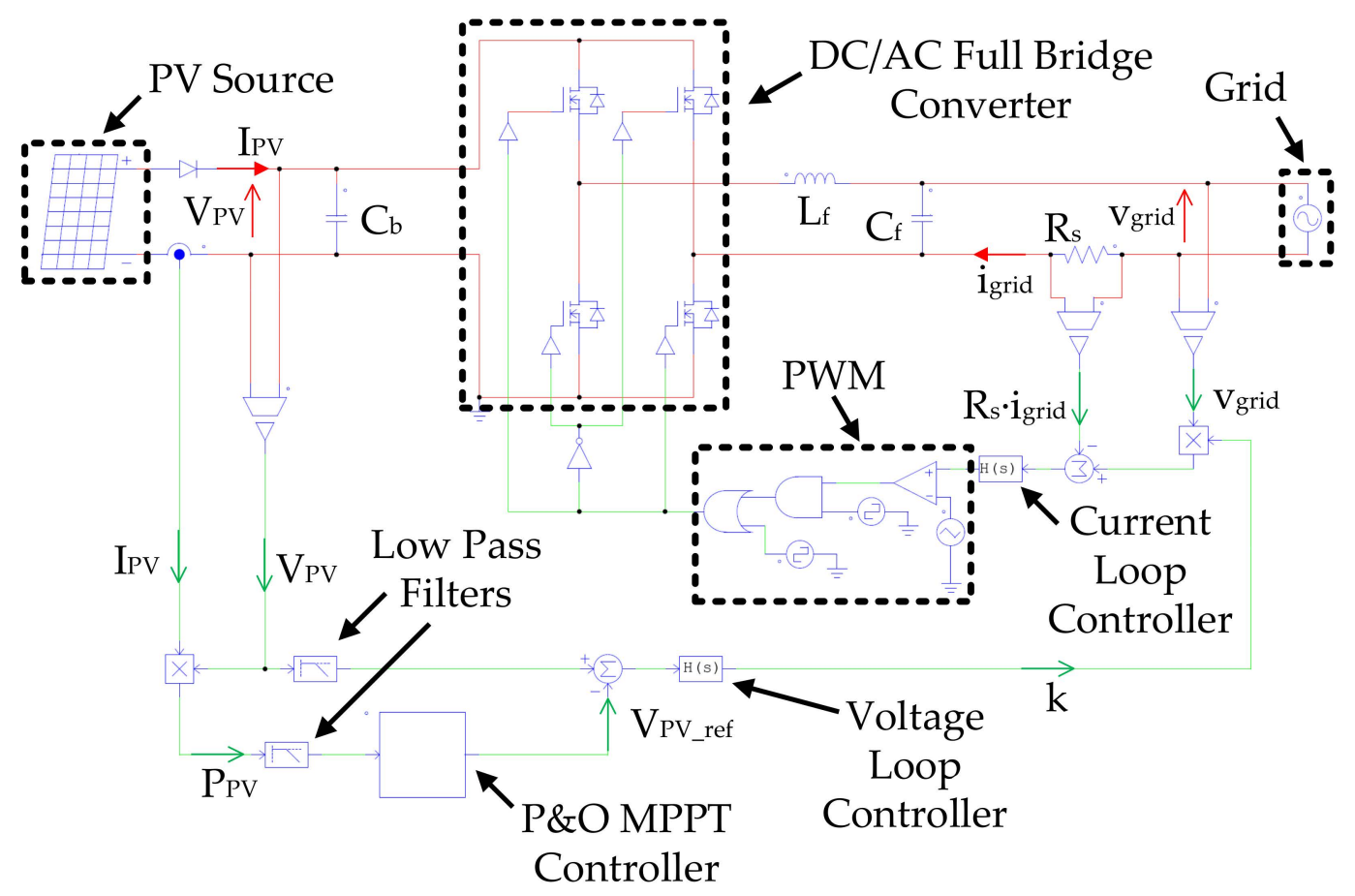

Figure 1. Single-stage grid-connected photovoltaic (PV) system equipped with the perturb and observe (P\&O) maximum power point tracking (MPPT) technique.

A fast internal current control loop is aimed at injecting an AC current into the grid with a power factor ideally equal to one. The interested reader can find all the details concerning the proper design of such a control loop in [16]. In this paper, ideal working of the internal current control loop (zero error) is assumed, and therefore the following equation represents the starting point for the analysis:

$$
\mathrm{R}_{\mathrm{s}} \cdot \mathrm{i}_{\text {grid }}(\mathrm{t})=\mathrm{k}(\mathrm{t}) \cdot \mathrm{v}_{\text {grid }}(\mathrm{t}) \text {, }
$$

where $R_{S}$ is the sensing resistance, $v_{\text {grid }}(t)=\sqrt{2} \cdot V_{\text {grid }} \cdot \sin (2 \pi f \cdot t)$ is the grid voltage, and $f$ is the line frequency. It is worth noting that $\mathrm{k}(\mathrm{t})$ is a slowly varying signal [16], hence from (1) it is possible to state that $i_{\text {grid }}(t)=\sqrt{2} \cdot I_{\text {grid }} \cdot \sin (2 \pi f \cdot t)$, that is, $i_{\text {grid }}(t)$ and $v_{\text {grid }}(t)$ are in phase. The slowly varying signal, $k$, dictates the value of the average (over the period of the line frequency $f$ ) power, $P_{\text {grid, }}$, injected into the grid, i.e., the higher the value of $\mathrm{k}$, the higher the active power $\mathrm{P}_{\text {grid. }}$. In fact, it is

$$
\mathrm{P}_{\text {grid }}=\mathrm{I}_{\text {grid }} \cdot \mathrm{V}_{\text {grid }}=\frac{\mathrm{k}}{\mathrm{R}_{\mathrm{s}}} \cdot \mathrm{V}_{\text {grid }}^{2} \cdot
$$


A slow external voltage control loop is aimed at the proper regulation of the PV voltage, $\mathrm{V}_{\mathrm{PV}}$. The reference voltage, $\mathrm{V}_{\mathrm{PV} \_ \text {ref }}$, is provided, as shown in Figure 1 , by the MPPT controller $[18,19]$. It is worth noting, as shown in Figure 1, that two low-pass filters appear. One for the PV voltage, $\mathrm{V}_{\mathrm{PV}}$, and the other for the PV power, $\mathrm{P}_{\mathrm{PV}}$. Filtering is necessary in order to avoid errors of the MPPT technique, which can be deceived by the presence of harmonics (at the double of the line frequency and at the frequencies of switching harmonics). In addition, the working of the voltage control loop can be negatively affected by such harmonics. Henceforth, for brevity, we refer to $V_{P V}$ and $P_{P V}$ even if we indeed refer to their filtered versions.

As stated in the Introduction, the P\&O technique is one of the most exploited MPPT techniques since it is simple but nonetheless very efficient. The $\mathrm{P} \& \mathrm{O}$ algorithm operates by periodically changing, step-by-step, the reference voltage, $\mathrm{V}_{\mathrm{PV} \_ \text {ref, }}$ and by measuring the corresponding PV power, $\mathrm{P}_{\mathrm{PV}}=\mathrm{V}_{\mathrm{PV}} \cdot \mathrm{I}_{\mathrm{PV}}$ [18]. After each perturbation of $\mathrm{V}_{\mathrm{PV} \_ \text {ref, }}$, the $\mathrm{P} \& \mathrm{O}$ controller waits for the settling of the system steady-state and, subsequently, compares the new steady-state value of $\mathrm{P}_{\mathrm{PV}}$ with the older one in order to drive the operating point towards the MPP. In particular, if after a perturbation of $\mathrm{V}_{\mathrm{PV} \_ \text {ref }}$ the steady-state value of $\mathrm{P}_{\mathrm{PV}}$ has increased (decreased), it means that the operating point has moved towards (away from) the MPP. Therefore, the next perturbation of $\mathrm{V}_{\mathrm{PV} \_ \text {ref }}$ will have the same (opposite) sign as the previous perturbation, and so on. In summary, the control law that is implemented in the P\&O MPPT controller of Figure 1 is as follows:

$$
\begin{gathered}
\left.V_{P V \_r e f}(t)\right|_{(r+1) \cdot T_{P \& O}<t<(r+2) \cdot T_{P \& O}}=\left.V_{P V \_r e f}(t)\right|_{t=r \cdot T_{P \& O}}+ \\
+\left[\left.V_{P V \_r e f}(t)\right|_{t=r \cdot T_{P \& O}}-\left.V_{P V \_r e f}(t)\right|_{t=(r-1) \cdot T_{P \& O}}\right] \cdot \operatorname{sign}\left\{\left.P_{P V}(t)\right|_{t=r \cdot T_{P \& O}}-\left.P_{P V}(t)\right|_{t=(r-1) \cdot T_{P \& O}}\right\},
\end{gathered}
$$

where $\mathrm{r}$ is a growing integer index starting from $0(\mathrm{r}=0,1,2, \ldots)$. It is worth noting that in order to evaluate the PV extracted power, $\mathrm{P}_{\mathrm{PV}}$, appearing in (3), the PV current detection is necessary. Moreover, the objective of the $\mathrm{P} \& \mathrm{O}$ controller is the maximization of the power extracted by the PV source. Since the power stage efficiency $\eta_{\text {power_stage }}\left(V_{\mathrm{PV}}, \mathrm{P}_{\text {grid }}\right)$ [20-25] is not taken into account, the maximization of the PV power does not necessarily correspond to the maximization of the power $P_{\text {grid }}$ $=\mathrm{P}_{\mathrm{PV}} \cdot \eta_{\text {power_stage }}\left(\mathrm{V}_{\mathrm{PV}}, \mathrm{P}_{\text {grid }}\right)$ injected into the grid.

\section{T4S MPPT Technique}

As stated in the previous Section, $\mathrm{k}$ is a slowly varying signal [16] which dictates the value of the average power, $\mathrm{P}_{\text {grid }}$, in particular, the higher the $\mathrm{k}$ signal, the higher the amplitude of $\mathrm{i}_{\text {grid }}(\mathrm{t})$, and hence the higher the $\mathrm{P}_{\text {grid }}$. On the basis of such a consideration, the objective of the proposed T4S MPPT technique is represented by the identification of the PV voltage reference, $\mathrm{V}_{\mathrm{PV} \_ \text {ref, }}$ that leads to the maximization of the signal $\mathrm{k}$. A single-stage grid-connected PV system equipped with the T4S MPPT controller is shown in Figure 2. From Figure 2, it is evident that for the T4S MPPT technique to function it needs only the sensing of the PV voltage, $\mathrm{V}_{\mathrm{PV}}$, and the signal $\mathrm{k}$ that is an already available internal signal. Even in this case, two low-pass filters appear and the same considerations, made with reference to Figure 1, apply for the quantities, $\mathrm{k}$ and $\mathrm{V}_{\mathrm{PV}}$. It is worth noting, different from the P\&O technique, that no PV current detection is necessary. 


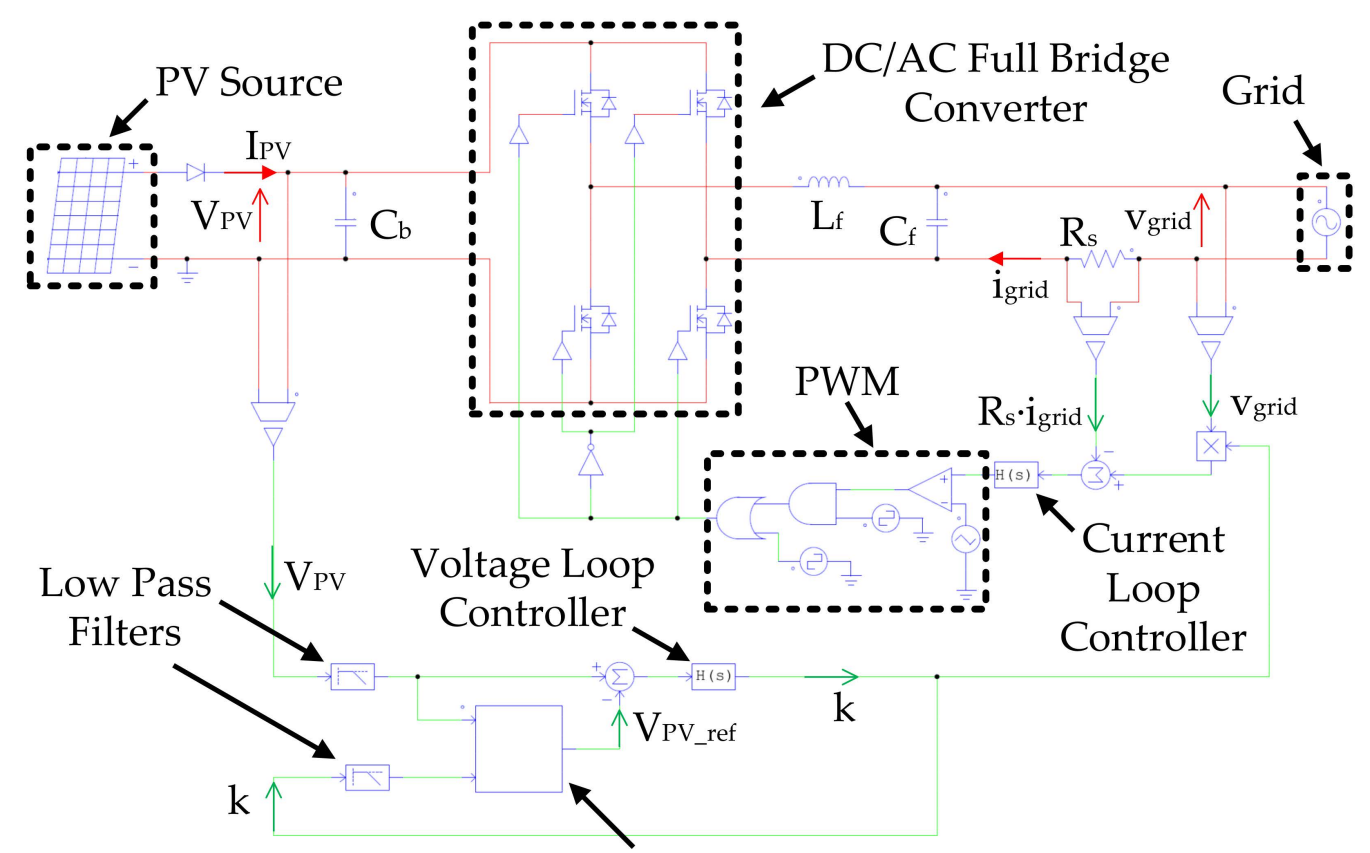

T4S MPPT Controller

Figure 2. Single-stage grid-connected PV system equipped with the T4S MPPT technique.

The operating principle of the T4S technique is well illustrated by the following control law that is implemented in the T4S controller of Figure 2:

$$
\mathrm{V}_{\mathrm{PV} \_ \text {ref }}(\mathrm{t})=\mathrm{V}_{\text {ref_0 }}+\left.\mathrm{K}_{\mathrm{I}} \cdot \int_{0}^{\mathrm{t}} \operatorname{sign}\left\{\frac{\mathrm{dk}(\tau)}{\mathrm{d} \tau} \cdot \frac{\mathrm{dV}_{\mathrm{PV}}(\tau)}{\mathrm{d} \tau}\right\}\right|_{\tau=\mathrm{r} \cdot \mathrm{T}_{\mathrm{SH}}} \mathrm{d} \tau \nabla \mathrm{t} \in\left[\mathrm{r} \cdot \mathrm{T}_{\mathrm{SH}} ;(\mathrm{r}+1) \cdot \mathrm{T}_{\mathrm{SH}}\right] \text {, }
$$

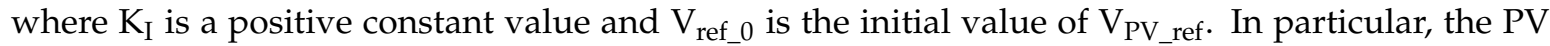
voltage reference, $\mathrm{V}_{\mathrm{PV} \_ \text {ref, }}$, provided by the T4S controller is the output of an integrator, as shown in Figure 3. Such an integrator processes a signal whose absolute value is the constant, $\mathrm{K}_{\mathrm{I}}$, and whose sign changes every $\mathrm{T}_{\mathrm{SH}}$ second according to the sign of the product between the time derivatives of $\mathrm{k}$ and $\mathrm{V}_{\mathrm{PV}}$. Hence, $\mathrm{V}_{\mathrm{PV} \_ \text {ref }}$ is a ramp function characterized by a slope equal to $\pm \mathrm{K}_{\mathrm{I}}$.

T4S MPPT Controller

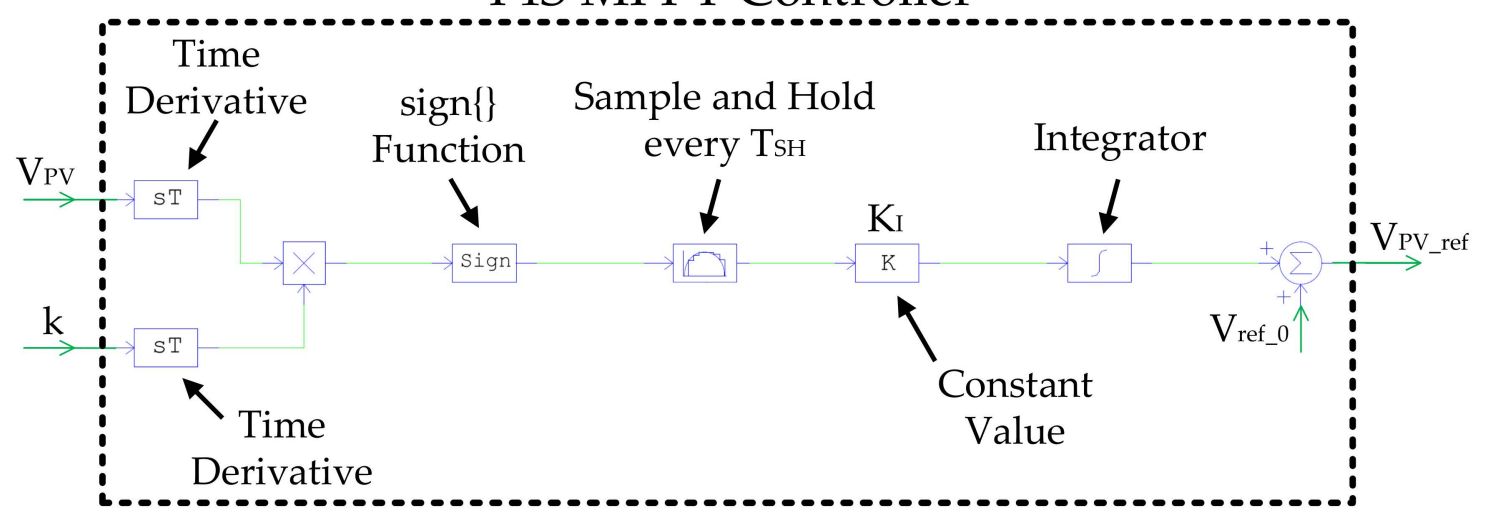

Figure 3. Block diagram of the proposed T4S MPPT technique.

In practice, the T4S MPPT technique is aimed at tracking the peak value of $\mathrm{k}$ with respect to $\mathrm{V}_{\mathrm{PV}}$ since, as already evidenced above, the higher the value of the $\mathrm{k}$ signal, the higher the $\mathrm{P}_{\text {grid }}$. Therefore, the output $\mathrm{V}_{\mathrm{PV} \_ \text {ref }}$ of the T4S controller will have a positive slope $\left(+\mathrm{K}_{\mathrm{I}}\right)$ in $\left[\mathrm{r} \cdot \mathrm{T}_{\mathrm{SH}^{+}}{ }^{+},(\mathrm{r}+1) \cdot \mathrm{T}_{\mathrm{SH}^{-}}\right]$if $\mathrm{k}$ and 
$\mathrm{V}_{\mathrm{PV}}$ are both increasing at $\mathrm{t}=\mathrm{r} \cdot \mathrm{T}_{\mathrm{SH}^{-}}$(case $\mathrm{A}$ in Figure $4 \mathrm{a}$, where the operating point is located at the left of the MPP and is moving towards the MPP) or if $k$ and $\mathrm{V}_{\mathrm{PV}}$ are both decreasing at $\mathrm{t}=\mathrm{r} \cdot \mathrm{T}_{\mathrm{SH}^{-}}{ }^{-}$(case $\mathrm{B}$ in Figure $4 \mathrm{a}$, where the operating point is located at the left of the MPP and is moving away from the MPP). Instead, $\mathrm{V}_{\mathrm{PV}_{-} \text {ref }}$ will have a negative slope $\left(-\mathrm{K}_{\mathrm{I}}\right)$ in $\left[\mathrm{r} \cdot \mathrm{T}_{\mathrm{SH}^{+}}{ }^{+},(\mathrm{r}+1) \cdot \mathrm{T}_{\mathrm{SH}^{-}}{ }^{-}\right]$if $\mathrm{k}$ is increasing and $\mathrm{V}_{\mathrm{PV}}$ is decreasing at $\mathrm{t}=\mathrm{r} \cdot \mathrm{T}_{\mathrm{SH}^{-}}$(case $\mathrm{C}$ in Figure 4a where the operating point is located the right of the MPP and it is moving towards the MPP) or if $k$ is decreasing and $V_{P V}$ is increasing (case $\mathrm{D}$ in Figure $4 \mathrm{a}$ where the operating point is located at the right of the MPP and it is moving away from the $\mathrm{MPP}$ ). In practice, the working of the T4S technique is based on the proper setting, every $\mathrm{T}_{\mathrm{SH}}$ second, of the sign of the slope of the photovoltaic voltage reference signal, $\mathrm{V}_{\mathrm{PV} \_ \text {ref, }}$, from which the name was chosen for the proposed MPPT technique.

At steady-state, in the neighborhood of the MPP, the T4S technique leads to a $\mathrm{V}_{\mathrm{PV}}$ ref waveform characterized by a piecewise ramp profile with a period equal to $2 \cdot \mathrm{T}_{\mathrm{SH}}$ and a peak-peak amplitude equal to $\mathrm{K}_{\mathrm{I}} \cdot \mathrm{T}_{\mathrm{SH}}$ (Figure $4 \mathrm{~b}$ ). Hence, the steady-state performance of the T4S technique is strictly linked to the values assumed by the two parameters, $\mathrm{T}_{\mathrm{SH}}$ and $\mathrm{K}_{\mathrm{I}}$. $\mathrm{T}_{\mathrm{SH}}$ must be greater than the settling time of the filtered versions of the two input signals $V_{P V}$ and $k$. Then, the proper value of $K_{I}$ can be identified on the basis of the maximum allowed steady-state variation $\Delta \mathrm{V}_{\mathrm{PV}}=\mathrm{K}_{\mathrm{I}} \cdot \mathrm{T}_{\mathrm{SH}}$ of the PV operating point. It is worth noting that the higher the value of $\Delta \mathrm{V}_{\mathrm{PV}}$, the higher the steady-state waste of available PV power.

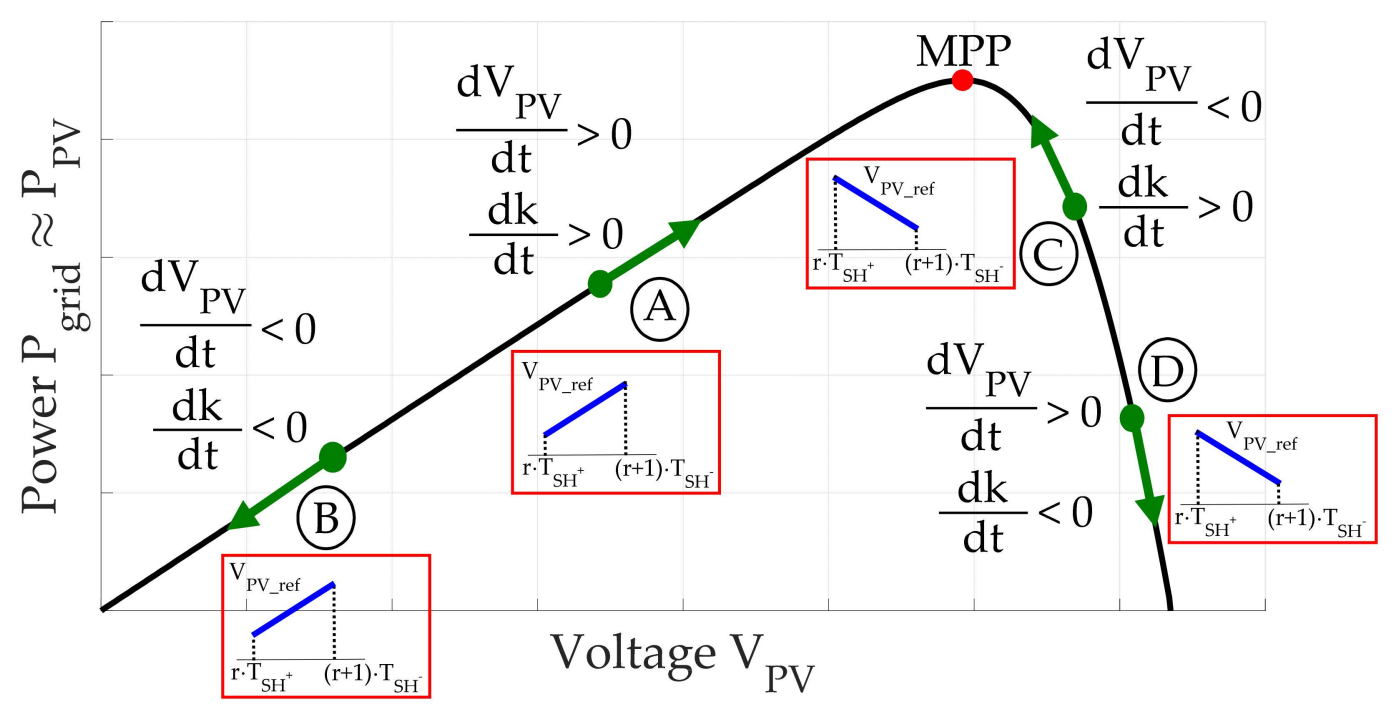

(a)

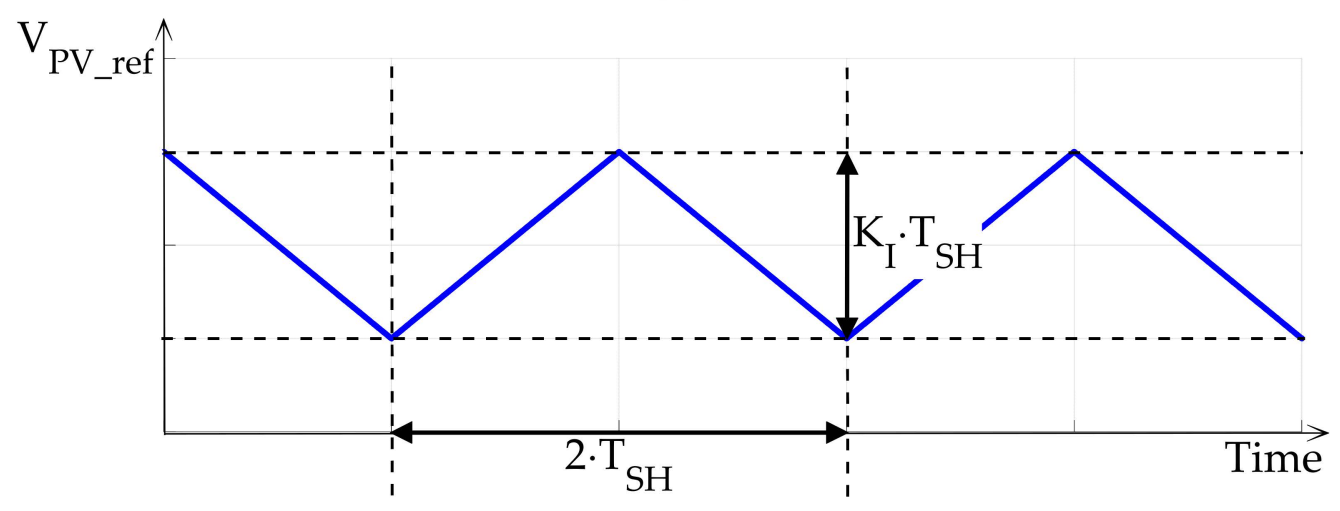

(b)

Figure 4. (a) The operation of the proposed T4S MPPT technique by assuming $\eta_{\text {power_stage }}\left(\mathrm{V}_{\mathrm{PV}}, \mathrm{P}_{\text {grid }}\right)$ $\cong 1$ and (b) piecewise ramp waveform assumed by the photovoltaic voltage reference signal, $V_{P V}$ ref, at the steady-state in the maximum power point (MPP). 


\section{Numerical Results}

In this section, numerical results concerning the working of a grid-connected single-stage PV system equipped with a T4S MPPT controller are reported and discussed. In particular, the system, as shown in Figure 2, has been implemented and tested in a PSIM environment [26]. The RMS grid voltage, $\mathrm{V}_{\text {grid }}$, was set equal to $230 \mathrm{~V}$ and the line frequency, $\mathrm{f}$, was set equal to $50 \mathrm{~Hz}$. The considered PV source is characterized, in STC, by PMPP_STC $=3058 \mathrm{~W}$ and VMPP_STC $=401.5 \mathrm{~V}$. With regard to the current control loop, its crossover frequency, $\mathrm{f}_{\mathrm{CI}}$, was set equal to $5 \mathrm{kHz}$, and the switching frequency, $\mathrm{f}_{\mathrm{SI}}$, of the PWM modulator has been set equal to $50 \mathrm{kHz}$. Moreover, $\mathrm{R}_{\mathrm{s}}=0.1 \Omega, \mathrm{C}_{\mathrm{b}}=10 \mathrm{mF}, \mathrm{L}_{\mathrm{f}}=330 \mu \mathrm{H}$, and $\mathrm{C}_{\mathrm{f}}=47 \mu \mathrm{F}$. With respect to the slow voltage control loop, its crossover frequency, $\mathrm{f}_{\mathrm{CV}}$, was set equal to $5 \mathrm{~Hz}$ and the low pass filters cut-off frequency, $\mathrm{f}_{\mathrm{LPF}}$, was set equal to $10 \mathrm{~Hz}$. The maximum allowed steady-state variation, $\Delta \mathrm{V}_{\mathrm{PV}}$, of the $\mathrm{PV}$ operating point was set equal to $10 \mathrm{~V}$; such a value leads to a maximum steady-state PV power waste equal to about $0.5 \%$.

The parameters of the T4S technique were identified as explained in the previous section. In particular, in [11] the interested reader can find a detailed analysis and discussion on the guidelines for the proper choice of perturbation periods in MPPT techniques with specific reference to the P\&O technique. Basically, such perturbation periods must be greater than the system settling time in order to avoid errors in the MPPT process. In practice, the same considerations also hold for the proposed T4S MPPT technique. In particular, in the considered case, the estimated system settling time, to within $5 \%$, is nearly equal to $0.26 \mathrm{~s}$, which is consistent with the crossover frequency $(5 \mathrm{~Hz})$ of the voltage control loop. Therefore, $\mathrm{T}_{\mathrm{SH}}=0.4 \mathrm{~s}$ was selected. It is worth noting that the influence of the chosen value of $\mathrm{T}_{\mathrm{SH}}$ on the performance of the proposed algorithm is such that, for a given $\mathrm{K}_{\mathrm{I}}$, the higher the $\mathrm{T}_{\mathrm{SH}}$ the slower the tracking process under time-varying irradiance conditions and the higher the waste of available energy under steady-state irradiance conditions. Then, given the value of $\mathrm{T}_{\mathrm{SH}}$, the proper value of $\mathrm{K}_{\mathrm{I}}$ can be identified on the basis of the maximum allowed steady-state variation, $\Delta \mathrm{V}_{\mathrm{PV}}$ $=\mathrm{K}_{\mathrm{I}} \cdot \mathrm{T}_{\mathrm{SH}}$, of the PV operating point, and, in particular, the higher the value of $\Delta \mathrm{V}_{\mathrm{PV}}$, the higher the steady-state maximum waste of available PV power. Since $\Delta V_{P V}$ was set equal to $10 \mathrm{~V}$, it is $K_{I}=25 \mathrm{~V} / \mathrm{s}$.

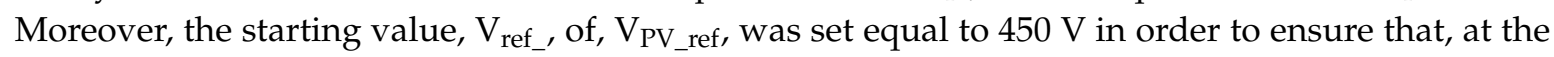
startup, the system works sufficiently far from the minimum allowed value of the DC input voltage of the full-bridge inverter that is equal to $\sqrt{2} \cdot 230 \mathrm{~V}=325 \mathrm{~V}$. It is worth noting that because of the unit power stage efficiency of the power electronics interface of the ideal system implemented and simulated in PSIM, the maximum value of $\mathrm{P}_{\text {grid }}$ is only obtained when the PV source operates in its MPP.

\subsection{Constant Irradiance}

The first set of simulations were carried out in order to show the correct working of the proposed T4S MPPT technique and its ability to identify the maximum power point (MPP) under stationary irradiance conditions. In particular, a constant irradiance level, $\mathrm{S}=1000 \mathrm{~W} / \mathrm{m}^{2}$, was considered. In such a condition the PV source is characterized by $\mathrm{P}_{\mathrm{MPP}}=3058 \mathrm{~W}$ and $\mathrm{V}_{\mathrm{MPP}}=401.5 \mathrm{~V}$.

The following figures illustrate the behavior of the technique at the startup. In particular, in Figure 5 the PV extracted power is reported and compared with the available MPP power. 


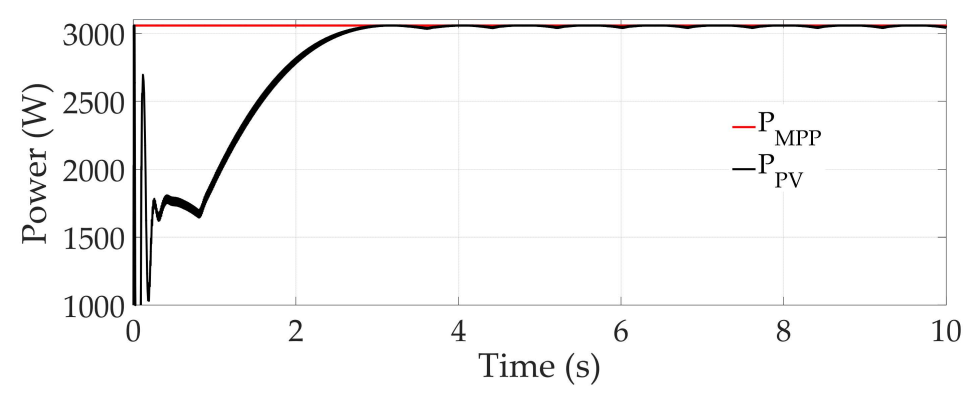

(a)

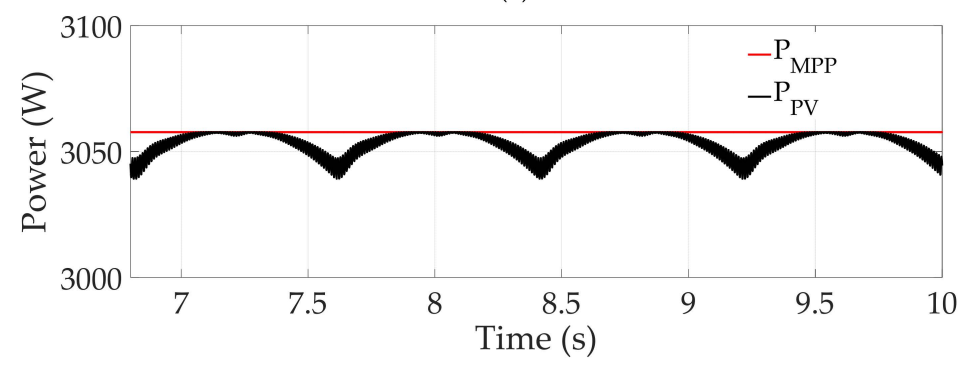

(b)

Figure 5. (a) Power extracted by adopting the T4S MPPT technique under a constant irradiance $\mathrm{S}=$ $1000 \mathrm{~W} / \mathrm{m}^{2}$ and (b) zoom of the steady-state behavior.

From the analysis of Figure 5a, the ability of the proposed technique to identify, after about $4 \mathrm{~s}$, the MPP without errors is evident. In Figure $5 b$, a zoom of the steady-state behavior is reported. It is evident, as stated in the previous section, that the T4S technique leads to a periodic oscillation of the extracted power due to the periodic piecewise ramp profile of $\mathrm{V}_{\mathrm{PV}_{\_} \text {ref, }}$ as shown in Figure 6a. Moreover, as predicted, the maximum waste of power due to such an oscillation around the MPP is equal to about $0.5 \%$, i.e., $(3058 \mathrm{~W}-3042 \mathrm{~W}) / 3042 \mathrm{~W}$, as shown in Figure $5 \mathrm{~b}$, where $3058 \mathrm{~W}$ is the $\mathrm{P}_{\mathrm{MPP}}$ and $3042 \mathrm{~W}$ represents the lowest level of the instantaneous extracted power. Moreover, from observations of Figure $6 \mathrm{~b}$, it is clear, as explained in the previous Section, that the voltage, $\mathrm{V}_{\mathrm{PV} \_}$ref, is characterized by a period equal to $2 \cdot \mathrm{T}_{\mathrm{SH}}=0.8 \mathrm{~s}$ and a peak-peak amplitude equal to $\mathrm{K}_{\mathrm{I}} \cdot \mathrm{T}_{\mathrm{SH}}=10 \mathrm{~V}$.

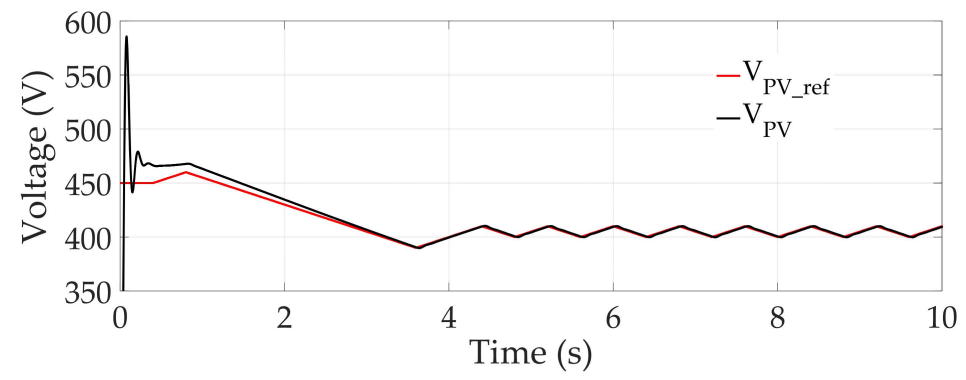

(a)

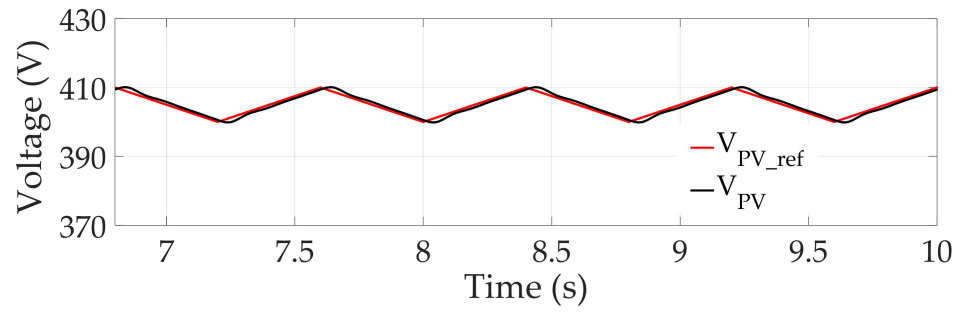

(b)

Figure 6. (a) Voltages, $\mathrm{V}_{\mathrm{PV}_{-} \text {ref }}$ and $\mathrm{V}_{\mathrm{PV}}$, obtained under a constant irradiance $\mathrm{S}=1000 \mathrm{~W} / \mathrm{m}^{2}$ and (b) zoom of the steady-state behavior. 


\subsection{Time-Varying Irradiance}

The second set of simulations were carried out in order to test the ability of the T4S MPPT technique to track the MPP under time-varying irradiance conditions. In particular, the operation of the T4S technique was tested by adopting the irradiance profile, as shown in Figure 7. The considered irradiance exhibits a step change from $S=1000 \mathrm{~W} / \mathrm{m}^{2}$ to $S=500 \mathrm{~W} / \mathrm{m}^{2}$ at $\mathrm{t}=5 \mathrm{~s}$ and back from $\mathrm{S}=500 \mathrm{~W} / \mathrm{m}^{2}$ to $\mathrm{S}=1000 \mathrm{~W} / \mathrm{m}^{2}$ at $\mathrm{t}=10 \mathrm{~s}$. At $\mathrm{S}=1000 \mathrm{~W} / \mathrm{m}^{2}$, it is $\mathrm{P}_{\mathrm{MPP}}=3058 \mathrm{~W}$ and $\mathrm{V}_{\mathrm{MPP}}=401.5 \mathrm{~V}$ and at $\mathrm{S}=500 \mathrm{~W} / \mathrm{m}^{2}$, it is $\mathrm{P}_{\mathrm{MPP}}=1598 \mathrm{~W}$ and $\mathrm{V}_{\mathrm{MPP}}=428 \mathrm{~V}$.

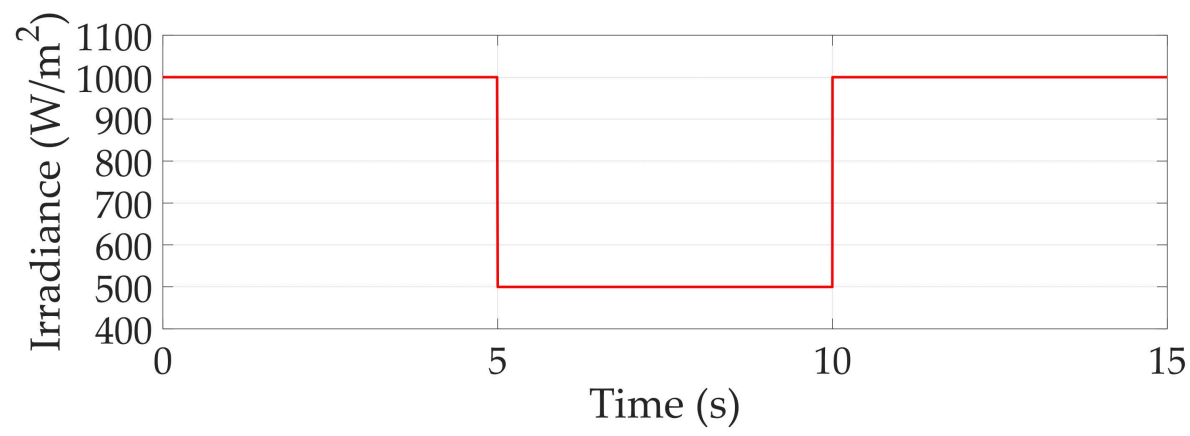

Figure 7. Time-varying irradiance profile.

The results of the numerical tests under the time-varying irradiance profile shown in Figure 7 are reported in the following figures. In particular, in Figure 8, the PV extracted power is reported and compared with the available MPP power. In Figure 9, the voltage, $\mathrm{V}_{\mathrm{PV} \_ \text {ref }}$, is reported together with the PV voltage, $\mathrm{V}_{\mathrm{PV}}$.

The previous figures show that the proposed MPPT technique is able to quickly track the MPP after any irradiance step variation.

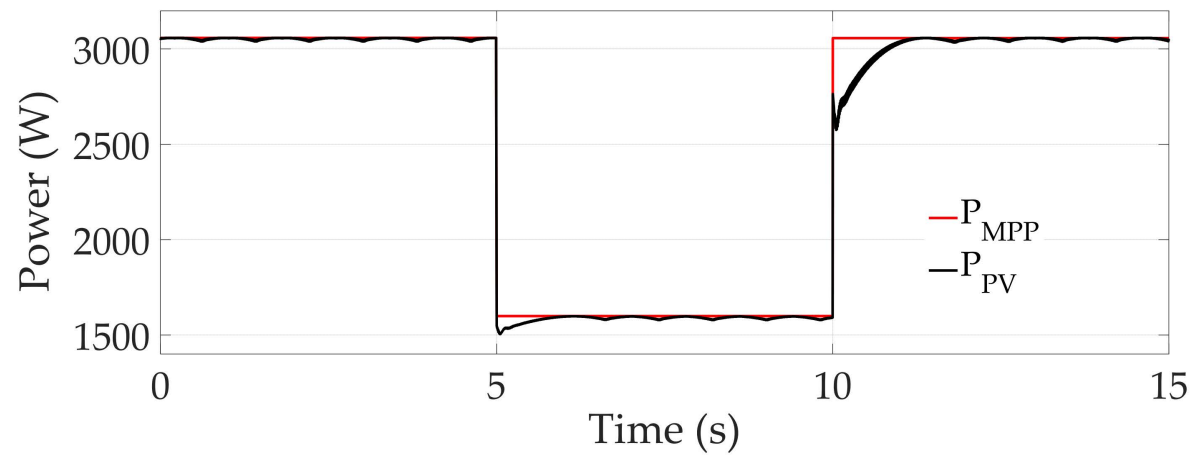

Figure 8. Power extracted by adopting the T4S technique under the irradiance profile of Figure 7.

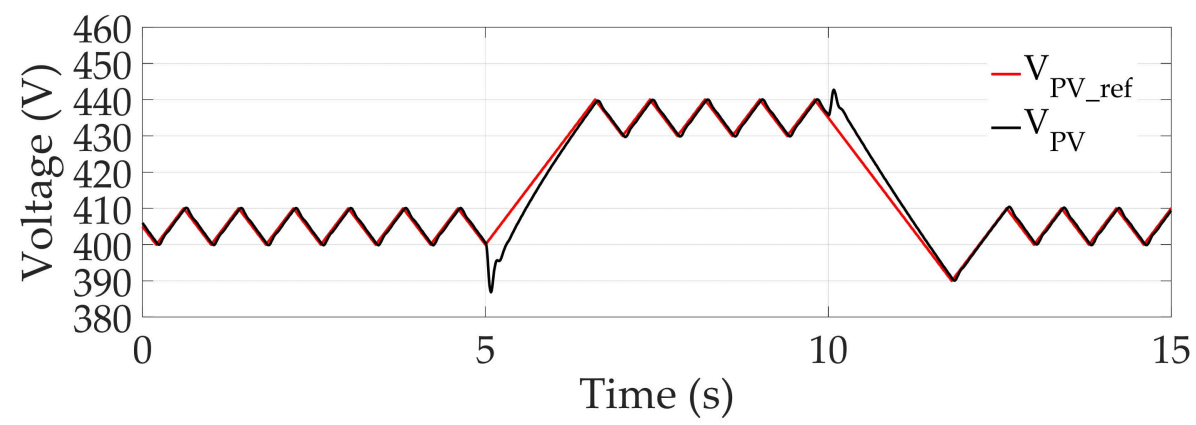

Figure 9. $\mathrm{V}_{\mathrm{PV} \_ \text {ref }}$ and $\mathrm{V}_{\mathrm{PV}}, \mathrm{T} 4 \mathrm{~S}$ technique under the irradiance profile shown in Figure 7. 


\section{Comparison between the T4S MPPT Technique and the P\&O MPPT Technique}

The last set of numerical tests were carried out in order to compare the performance of the proposed T4S MPPT technique with that of the traditional P\&O algorithm. to this aim, the system shown in Figure 1 was implemented and tested in a PSIM environment with the same values for the parameters as adopted in the previous section. The parameters of the $\mathrm{P} \& \mathrm{O}$ algorithm $\left(\mathrm{T}_{\mathrm{P} \& \mathrm{O}}, \Delta \mathrm{V}_{\mathrm{PV} \_ \text {ref }}\right.$, and $\mathrm{V}_{\text {ref_o}}$ ) were chosen on the basis of the guidelines reported in the literature [11] and in order to obtain the same steady-state maximum waste of power $(0.5 \%)$ considered in the previous section, in particular, $\mathrm{T}_{\mathrm{P \& O}}=0.4 \mathrm{~s}, \Delta \mathrm{V}_{\mathrm{PV} \_ \text {ref }}=10 \mathrm{~V}$, and $\mathrm{V}_{\text {ref_0 }}=450 \mathrm{~V}$. It is worth noting that the values of the parameters that have been chosen for the $\mathrm{P} \& \mathrm{O}$ technique fully ensure a fair comparison with the T4S MPPT technique.

In the following, the symbol $\kappa_{\mathrm{d} \%}$ indicates the quantity $\left(\mathrm{P}_{\mathrm{T} 4 \mathrm{~S}-\mathrm{d}} / \mathrm{P}_{\mathrm{P \&}-\mathrm{O}}-1\right) \cdot 100 \%$ where $\mathrm{P}_{\mathrm{T} 4 \mathrm{~S}-\mathrm{d}}$ is the average extracted power in dynamic conditions by adopting the T4S technique, and $\mathrm{P}_{\mathrm{P} \& \mathrm{O}-\mathrm{d}}$ is the average extracted power under the same dynamic conditions by adopting the $\mathrm{P} \& \mathrm{O}$ technique. "Dynamic conditions" mean working conditions taking place in the interval of time occurring between an event associated with a change of the irradiance conditions and the subsequent settling instant of steady-state periodic conditions. In particular, steady-state periodic conditions associated with the $\mathrm{T} 4 \mathrm{~S}$ technique are characterized by a piecewise ramp voltage behavior with period equal to $2 \cdot \mathrm{T}_{\mathrm{SH}}$, as discussed in Section 3 and reported in Figure 4b. Instead, steady-state periodic conditions associated with the $\mathrm{P} \& \mathrm{O}$ technique are characterized by a three-level voltage behavior with period equal to 3. $\mathrm{T}_{\mathrm{P \& O}}$ [11]. It is worth noting that since the settling instant is, in general, different for the two MPPT techniques, the highest settling instant will be considered for the evaluation of $\mathrm{k}_{\mathrm{d} \%}$. In addition, the symbol $\mathrm{k}_{\mathrm{ss}} \%$ indicates the quantity $\left(\mathrm{P}_{\mathrm{T} 4 \mathrm{~S}-\mathrm{ss}} / \mathrm{P}_{\mathrm{P \&}} \mathrm{O}\right.$-ss -1$) \cdot 100 \%$, where $\mathrm{P}_{\mathrm{T} 4 \mathrm{~S}-\mathrm{ss}}$ is the average extracted power in steady-state periodic conditions by adopting the T4S technique, for a given irradiance level, and $\mathrm{P}_{\mathrm{P} \& \mathrm{O}-\mathrm{ss}}$ is the average extracted power in steady-state periodic conditions by adopting the $\mathrm{P} \& \mathrm{O}$ technique for the same irradiance level.

\subsection{Stationary Irradiance Conditions}

The powers extracted by adopting the T4S and the P\&O MPPT techniques under a constant irradiance $\left(S=1000 \mathrm{~W} / \mathrm{m}^{2}\right)$ are reported together in Figure 10a. It is evident that both techniques need nearly the same time, at the start up, to reach the MPP. Such a startup can be seen as a step change of the irradiance level from 0 to $1000 \mathrm{~W} / \mathrm{m}^{2}$ and is characterized by a settling instant equal to $4 \mathrm{~s}, \mathrm{P}_{\mathrm{T} 4 \mathrm{~S}-\mathrm{d}}=2519 \mathrm{~W}, \mathrm{P}_{\mathrm{P} \& \mathrm{O}-\mathrm{d}}=2345 \mathrm{~W}$, and hence $\mathrm{\kappa}_{\mathrm{d} \%}=7.4 \%$. In addition, by looking at the zoom of Figure 10b, no remarkable difference in the steady-state efficiencies of the two MPPT techniques can be identified, although, indeed, the T4S performance is slightly better. In particular, $\mathrm{P}_{\mathrm{T} 4 \mathrm{~S} \text {-ss }}=3053 \mathrm{~W}$, $\mathrm{P}_{\mathrm{P} \& \mathrm{O}-\mathrm{ss}}=3048 \mathrm{~W}$, and hence $\mathrm{K}_{\mathrm{ss} \%}=0.16 \%$.

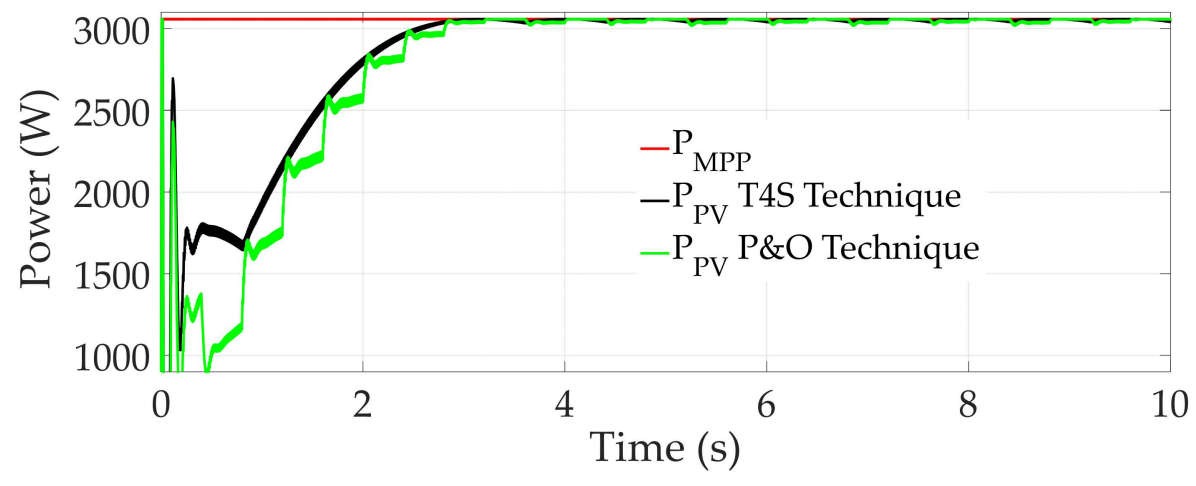

$(\mathbf{a})$

Figure 10. Cont. 


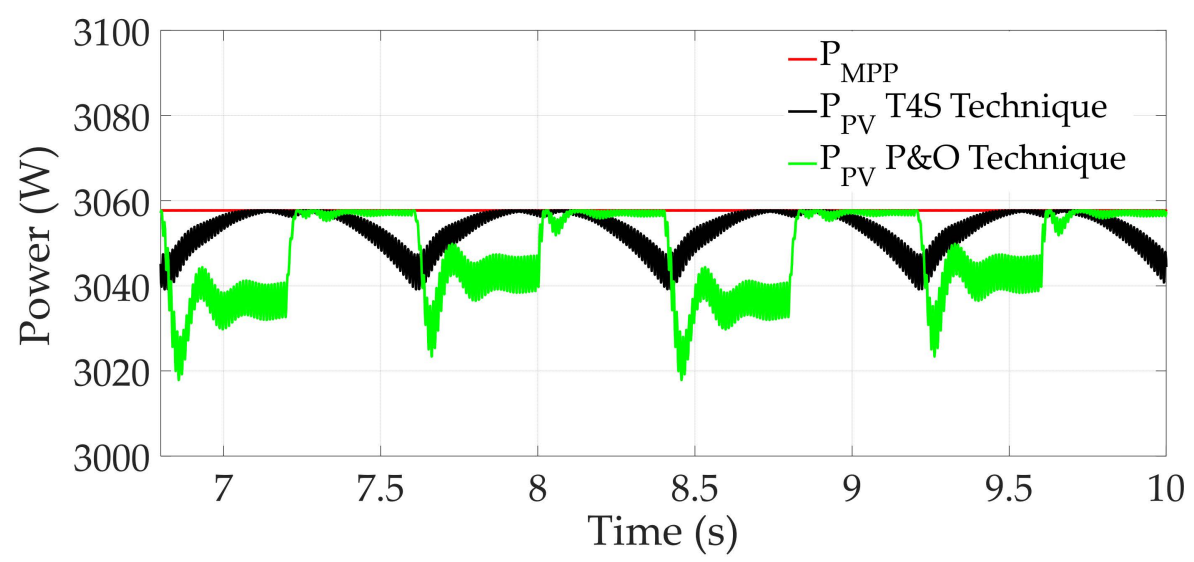

(b)

Figure 10. (a) Power extracted by adopting the T4s and the P\&O MPPT techniques under a constant irradiance $\mathrm{S}=1000 \mathrm{~W} / \mathrm{m}^{2}$ and $(\mathbf{b})$ zoom of the steady-state behavior.

An interesting difference between the two MPPT techniques can be evidenced by observing Figure $11 \mathrm{a}$ and, in particular, its zoom in Figure $11 \mathrm{~b}$. In this figure, $\mathrm{V}_{\mathrm{PV} \_}$ref and $\mathrm{V}_{\mathrm{PV}}$ are reported for both of the MPPT techniques. It is clear for the $\mathrm{P} \& \mathrm{O}$ case, at steady-state, $\mathrm{V}_{\mathrm{PV} \_ \text {ref }} \approx \mathrm{V}_{\mathrm{PV}}$ oscillates around the MPP by assuming, as expected, the following three values: $V_{M P P}-\Delta V_{P V}, V_{M P P}$, and $V_{M P P}$ $+\Delta \mathrm{V}_{\mathrm{PV}}$ [18]. Instead, in the T4S case, $\mathrm{V}_{\mathrm{PV} \_ \text {ref }} \approx \mathrm{V}_{\mathrm{PV}}$ exhibits a piecewise linear behavior with values belonging to the range $\left[\mathrm{V}_{\mathrm{MPP}}\right.$ and $\left.\mathrm{V}_{\mathrm{MPP}}+\Delta \mathrm{V}_{\mathrm{PV}}\right]$. In other words, the T4S operating point is always located at the right of the MPP.

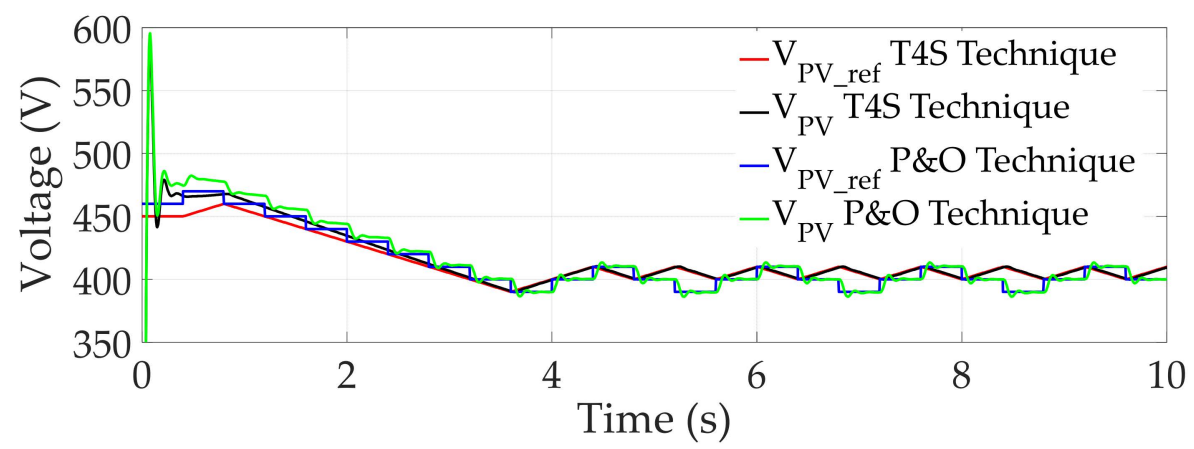

(a)

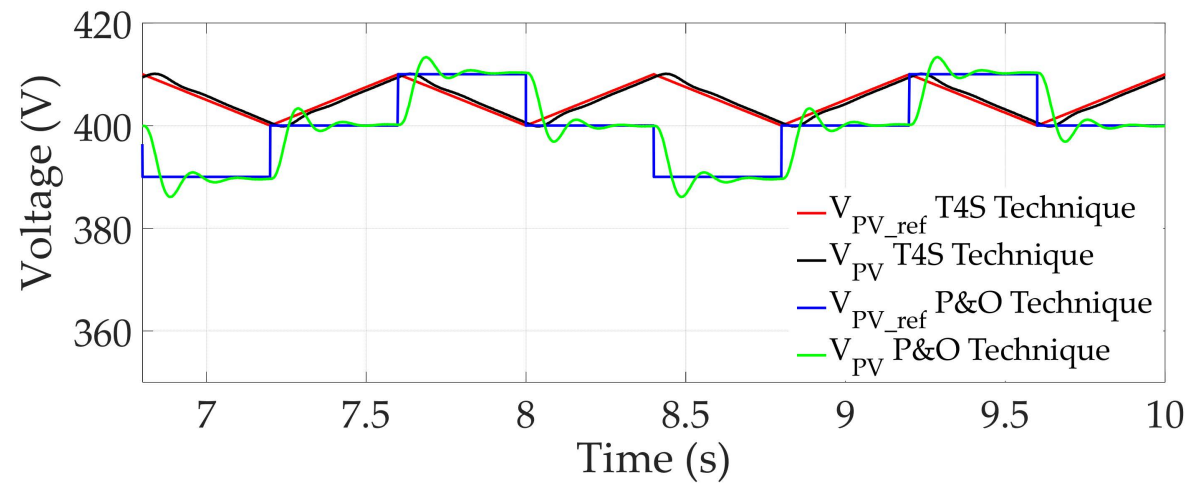

(b)

Figure 11. (a) $\mathrm{V}_{\mathrm{PV} \_ \text {ref }}$ and $\mathrm{V}_{\mathrm{PV}}, \mathrm{T} 4 \mathrm{~S}$ and $\mathrm{P} \& \mathrm{O} \mathrm{MPPT}$ techniques under a constant irradiance $\mathrm{S}=1000 \mathrm{~W} / \mathrm{m}^{2}$ and $(\mathbf{b})$ zoom of the steady-state behavior. 


\subsection{Time-Varying Irradiance}

The performances of the two MPPT techniques were compared also under time-varying irradiance conditions. The adopted time-varying irradiance profile is shown in Figure 7. The powers extracted by adopting the T4S and the P\&O MPPT techniques under such an irradiance profile are reported together in Figure 12. In Figure 13, $\mathrm{V}_{\mathrm{PV} \_ \text {ref }}$ and $\mathrm{V}_{\mathrm{PV}}$ are reported for both of the MPPT techniques. From the abovementioned figures, it is evident the P\&O MPPT technique is outperformed by the T4S technique, at least in correspondence to the irradiance positive step.

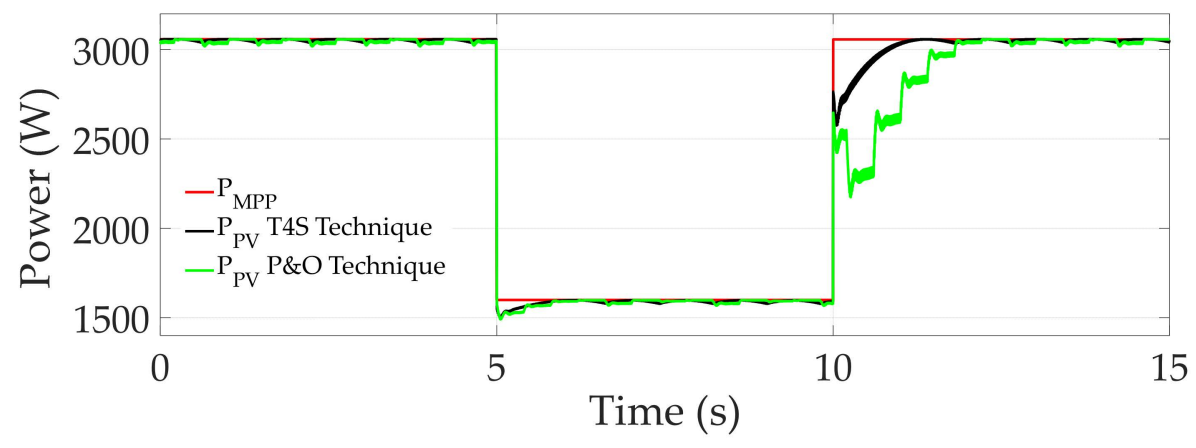

Figure 12. Power extracted by adopting the T4S and the P\&O MPPT techniques under the irradiance profile of Figure 7.

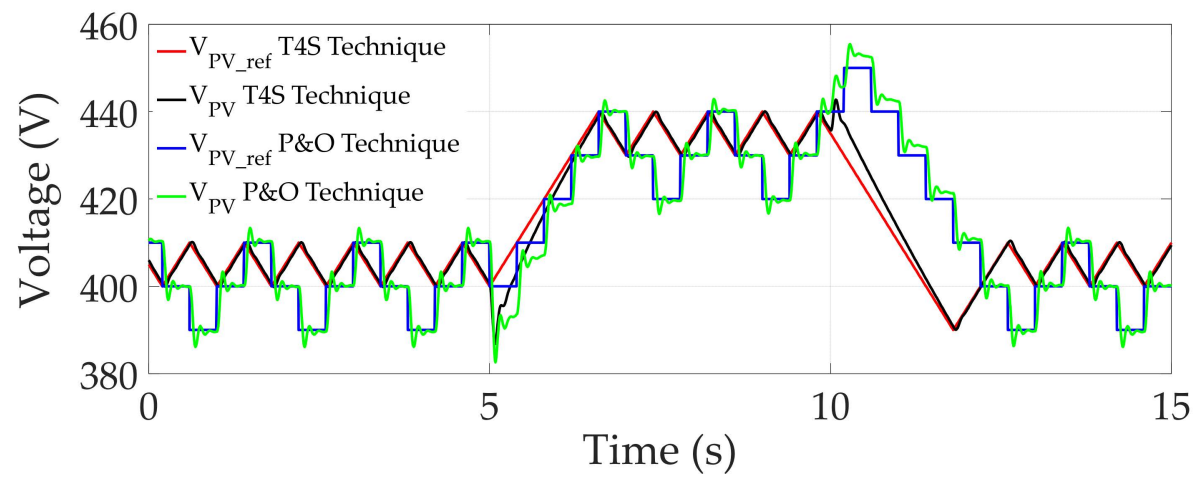

Figure 13. $\mathrm{V}_{\mathrm{PV} \_ \text {ref }}$ and $\mathrm{V}_{\mathrm{PV}}, \mathrm{T} 4 \mathrm{~S}$ and $\mathrm{P} \& \mathrm{O} \mathrm{MPPT}$ techniques under the irradiance profile shown in Figure 7.

From the above figures, it is evident the P\&O MPPT technique is outperformed by the T4S technique, at least in correspondence to the irradiance positive step. In particular, in correspondence of the irradiance negative step occurring at $\mathrm{t}=5 \mathrm{~s}$ the following values have been obtained: settling instant equal to $6.2 \mathrm{~s}, \mathrm{P}_{\mathrm{T} 4 \mathrm{~S}-\mathrm{d}}=1571 \mathrm{~W}, \mathrm{P}_{\mathrm{P} \& \mathrm{O}-\mathrm{d}}=1561 \mathrm{~W}$, and hence $\mathrm{\kappa}_{\mathrm{d} \%}=0.64 \%$. In correspondence to the irradiance positive step occurring at $\mathrm{t}=10 \mathrm{~s}$ the following values have been obtained: settling instant equal to $12.2 \mathrm{~s}, \mathrm{P}_{\mathrm{T} 4 \mathrm{~S}-\mathrm{d}}=2971 \mathrm{~W}, \mathrm{P}_{\mathrm{P} \& \mathrm{O}-\mathrm{d}}=2721 \mathrm{~W}$, and hence $\mathrm{k}_{\mathrm{d} \%}=9.2 \%$.

\section{Conclusions}

A novel MPPT technique, T4S (a technique based on the proper setting of the sign of the slope of the photovoltaic voltage reference signal), has been presented and discussed in this paper. Such a technique is specifically designed with reference to a single-stage grid-connected PV system. Its performance has been numerically compared to a benchmark MPPT technique, the P\&O technique. The tracking efficiencies of the two techniques are more or less comparable, however, the T4S technique has a slightly better performance under both stationary and time-varying irradiance conditions. Furthermore, the T4S technique is characterized by the following two advantages with respect to the $\mathrm{P} \& \mathrm{O}$ technique: There is no need for PV current detection and the power stage efficiency profile is automatically taken 
into account. In other words, the T4S technique allows the tracking of the maximum average power injected into the grid rather than the maximum instantaneous power extracted by the PV source.

Author Contributions: Conceptualization, L.C. and M.V.; methodology, L.C. and M.V.; software, L.C. and M.V.; validation, L.C. and M.V.; formal analysis, L.C. and M.V.; investigation, L.C. and M.V.; resources, L.C. and M.V.; data curation, L.C. and M.V.; writing-original draft preparation, L.C. and M.V.; writing-review and editing, L.C. and M.V.; visualization, L.C. and M.V.

Funding: This research was partially funded by the "VALERE" research program of the Università della Campania "Luigi Vanvitelli".

Conflicts of Interest: The authors declare no conflict of interest. The funders had no role in the design of the study; in the collection, analyses, or interpretation of data; in the writing of the manuscript, or in the decision to publish the results.

\section{References}

1. Pathy, S.; Subramani, C.; Sridhar, R.; Thentral, T.M.T.; Padmanaban, S. Nature-Inspired MPPT Algorithms for Partially Shaded PV Systems: A Comparative Study. Energies 2019, 12, 1451. [CrossRef]

2. Balato, M.; Costanzo, L.; Vitelli, M. Chapter 5-DMPPT PV System: Modeling and Control Techniques. In Advances in Renewable Energies and Power Technologies; Yahyaoui, I., Ed.; Elsevier: Edinburgh, UK, 2018; pp. 163-205, ISBN 9780128129593. [CrossRef]

3. Saravanan, S.; Babu, N.R. Maximum power point tracking algorithms for photovoltaic system-A review. Renew. Sustain. Energy Rev. 2016, 57, 192-204. [CrossRef]

4. Balato, M.; Costanzo, L.; Marino, P.; Rubino, G.; Rubino, L.; Vitelli, M. Modified TEODI MPPT Technique: Theoretical Analysis and Experimental Validation in Uniform and Mismatching Conditions. IEEE J. Photovolt. 2017, 7, 604-613. [CrossRef]

5. Du, Y.; Yan, K.; Ren, Z.; Xiao, W. Designing Localized MPPT for PV Systems Using Fuzzy-Weighted Extreme Learning Machine. Energies 2018, 11, 2615. [CrossRef]

6. Yazdani, A.; Di Fazio, A.R.; Ghoddami, H.; Russo, M.; Kazerani, M.; Jatskevich, J.; Strunz, K.; Leva, S.; Martinez, J.A. Modeling Guidelines and a Benchmark for Power System Simulation Studies of Three-Phase Single-Stage Photovoltaic Systems. IEEE Trans. Power Deliv. 2011, 26, 1247-1264. [CrossRef]

7. Tan, C.W.; Green, T.C.; Hernandez-Aramburo, C.A. Analysis of perturb and observe maximum power point tracking algorithm for photovoltaic applications. In Proceedings of the 2008 IEEE 2nd International Power and Energy Conference, Johor Bahru, Malaysia, 1-3 December 2008; pp. 237-242. [CrossRef]

8. Carrasco, M.; Mancilla-David, F. Maximum power point tracking algorithms for single-stage photovoltaic power plants under time-varying reactive power injection. Sol. Energy 2016, 132, 321-331. [CrossRef]

9. Kouro, S.; Leon, J.I.; Vinnikov, D.; Franquelo, L.G. Grid-Connected Photovoltaic Systems: An Overview of Recent Research and Emerging PV Converter Technology. IEEE Ind. Electron. Mag. 2015, 9, 47-61. [CrossRef]

10. Li, L.; Wang, H.; Chen, X.; Bukhari, A.A.S.; Cao, W.; Chai, L.; Li, B. High Efficiency Solar Power Generation with Improved Discontinuous Pulse Width Modulation (DPWM) Overmodulation Algorithms. Energies 2019, 12, 1765. [CrossRef]

11. Femia, N.; Petrone, G.; Spagnuolo, G.; Vitelli, M. Optimization of perturb and observe maximum power point tracking method. IEEE Trans. Power Electron. 2005, 20, 963-973. [CrossRef]

12. Femia, N.; Fortunato, M.; Lisi, G.; Petrone, G.; Spagnuolo, G.; Vitelli, M. Guidelines for the Optimization of the P\&O Technique in Grid-connected Double-stage Photovoltaic Systems. In Proceedings of the 2007 IEEE International Symposium on Industrial Electronics, Vigo, Spain, 4-7 June 2007; pp. 2420-2425. [CrossRef]

13. Rey-Boué, A.B.; Guerrero-Rodríguez, N.F.; Stöckl, J.; Strasser, T.I. Modeling and Design of the Vector Control for a Three-Phase Single-Stage Grid-Connected PV System with LVRT Capability according to the Spanish Grid Code. Energies 2019, 12, 2899. [CrossRef]

14. Jain, S.; Agarwal, V. Comparison of the performance of maximum power point tracking schemes applied to single-stage grid-connected photovoltaic systems. IET Electr. Power Appl. 2007, 1, 753-762. [CrossRef]

15. Wu, B.; Zhao, Z.; Liu, J. A Single-Stage Three-Phase Grid-Connected Photovoltaic System with Modified MPPT Method and Reactive Power Compensation. IEEE Trans. Energy Convers. 2007, 22, 881-886. [CrossRef]

16. Erickson, R.W.; Maksimovic, D. Fundamentals of Power Electronics, 2nd ed.; Kluwer: Norwell, MA, USA, 2001. 
17. Su, M.; Luo, C.; Hou, X.; Yuan, W.; Liu, Z.; Han, H.; Guerrero, J.M. A Communication-Free Decentralized Control for Grid-Connected Cascaded PV Inverters. Energies 2018, 11, 1375. [CrossRef]

18. Balato, M.; Costanzo, L.; Vitelli, M. Maximum Power Point Tracking Techniques. In Wiley Encyclopedia of Electrical and Electronics Engineering; Wiley Online Library: Hoboken, NJ, USA, 2016; pp. 1-26, ISBN 9780471346081. [CrossRef]

19. Balato, M.; Costanzo, L.; Marino, P.; Rubino, L.; Vitelli, M. Dual implementation of the MPPT technique TEODI: Uniform and mismatching operating conditions. In Proceedings of the 2015 International Conference on Clean Electrical Power (ICCEP 2015), Taormina, Italy, 16-18 June 2015; pp. 422-429. [CrossRef]

20. Pearsall, N.M. (Ed.) 1-Introduction to photovoltaic system performance. In The Performance of Photovoltaic (PV) Systems; Woodhead Publishing: Cambridge, UK, 2017; pp. 1-19, ISBN 9781782423362. [CrossRef]

21. Demoulias, C. A new simple analytical method for calculating the optimum inverter size in grid-connected PV plants. Electr. Power Syst. Res. 2010, 80, 1197-1204. [CrossRef]

22. Zeb, K.; Khan, I.; Uddin, W.; Khan, M.A.; Sathishkumar, P.; Busarello, T.D.C.; Ahmad, I.; Kim, H.J. A Review on Recent Advances and Future Trends of Transformerless Inverter Structures for Single-Phase Grid-Connected Photovoltaic Systems. Energies 2018, 11, 1968. [CrossRef]

23. Li, H.; Wen, C.; Chao, K.-H.; Li, L.-L. Research on Inverter Integrated Reactive Power Control Strategy in the Grid-Connected PV Systems. Energies 2017, 10, 912. [CrossRef]

24. Sechilariu, M.; Locment, F. (Eds.) Chapter 1-Connecting and Integrating Variable Renewable Electricity in Utility Grid. In Urban DC Microgrid; Butterworth-Heinemann: Waltham, UK, 2016; pp. 1-33, ISBN 9780128037362. [CrossRef]

25. Silvestre, S. Chapter IIA-4-Review of System Design and Sizing Tools. In Practical Handbook of Photovoltaics, 2nd ed.; McEvoy, A., Markvart, T., Castañer, L., Eds.; Academic Press: Cambridge, MA, USA, 2012; pp. 673-694, ISBN 9780123859341. [CrossRef]

26. PSIM. Available online: https://powersimtech.com/ (accessed on 26 November 2019).

(C) 2019 by the authors. Licensee MDPI, Basel, Switzerland. This article is an open access article distributed under the terms and conditions of the Creative Commons Attribution (CC BY) license (http://creativecommons.org/licenses/by/4.0/). 